\title{
Surfactant components of marine organic matter as agents for biogeochemical fractionation and pollutant transport via marine aerosols
}

\author{
C. Oppo a , S. Bellandi a, N. Degli Innocenti ${ }^{\text {b }}$, A.M. Stortini ${ }^{\text {b }}$, G. Loglio ${ }^{\text {b }}$, \\ E. Schiavuta ${ }^{c}$, R. Cini ${ }^{b, *}$ \\ ${ }^{\text {a }}$ Public Health, Epidemiology and Environmental Analytical Chemistry, Analytical Chemistry Section, University of Florence, Via Gino \\ Capponi 9, 50121, Florence, Italy \\ ${ }^{\mathrm{b}}$ Laboratory of Technical Physical Chemistry, Department of Organic Chemistry, University of Florence, Via Gino Capponi 9, 50121, \\ Florence, Italy \\ c Department of Physics, University of Padua, Via Marzolo 8, 35131, Padua, Italy \\ Received 13 June 1997; accepted 4 August 1998
}

\begin{abstract}
The role of surfactant organic matter in marine aerosol production has been studied under conditions in which there is a large coverage of whitecaps on the sea surface. To improve the knowledge of matter exchange and pollutant recycling from the sea surface into the atmosphere, a spray drop adsorption model (SDAM) was developed and the validity of the proposed model verified by the following experimental results: (1) an increase of surfactant matter on the sea surface during rough sea conditions ('surface wave concentration'); (2) an (hyperbolic-like) increase of the enrichment ratio (ER) of surfactant fluorescent organic matter (SFOM), made up predominantly by humic substances (HS), as the particle size decrease; (3) a similar behaviour for elements with pollutant properties, and which are known to interact with HS and other surfactant materials, considered pollution tracers. An additional laboratory experiment, based on the adsorption model conditions, gives enrichment ratio greater than unity for $\mathrm{K}$ and $\mathrm{Ca}$. The first results on marine aerosols trapped in marine clouds (at $1000 \mathrm{~m}$ above sea level and at $100 \mathrm{~km}$ from the coast) seem to further support the proposed model and its ability to predict the transition from saline to almost entirely organic particles for the smaller fractions of marine aerosols. The possible contribution of these particles to the recycling and to the long range transport of pollutants via marine aerosols has been considered. (C) 1999 Elsevier Science B.V. All rights reserved.
\end{abstract}

Keywords: surfactant components; marine organic matter; marine aerosols; marine clouds; biogeochemical fractionation

Abbreviations: ER, Enrichment Ratio; HS, Humic Substances; MBAS, Methylene-Blue Active Substances; SDAM, Spray Drop Adsorption Model; SFOM, Surfactant Fluorescent Organic Matter; SOM, Surfactant Organic Matter

*orresponding author. Fax: +39-55-2476964; E-mail: loglio@chimorg.unifi.it

\section{Introduction}

It has been known for a long time that the composition of marine aerosol is different from that of bulk seawater. Some hypotheses were reported by Berg 
and Winchester (1978) to explain this unusual behaviour that leads to different results depending on the sampling technique, the sampling site and the sampling period. At present it is generally accepted that atmospheric aerosol is made up of a mixture of marine particles, crustal dust and particles derived from human activities.

On the other hand marine particles can change their composition because of the interaction of natural surfactants with elements and organic compounds which can also be pollutants (MacIntyre, 1970; Piotrowicz et al., 1979; Cini et al., 1993). According to the results of the first SEAREX project, Arimoto et al. (1989) concluded that "much knowledge concerning the biogeochemical cycle of trace components into the atmosphere and oceans is still in its formative stage', One of the main topics related to this subject is the correct evaluation of fluxes of matter into and from the sea surface. In our opinion it is also very important to understand the relationship of the atmospheric aerosol composition to its origin. For this purpose, a thorough study of the phenomena occurring in marine aerosols under the most intense marine aerosol production conditions is necessary.

In this paper, we proposed a model on the basis of physical adsorption principles and some preliminary experiments which appear to contribute to these studies by a new way of interpreting the small particle enrichment of organic matter and elements in marine aerosols. These findings could constitute a basis for understanding long range pollutant transport via marine aerosols, and provide a better evaluation of the air-sea exchange phenomena.

\section{Theory}

\subsection{The breaking wave as aerosol generator}

The most important step in marine aerosol production is considered to be gas-bubble collapse at the sea surface. This mechanism was carefully analysed by MacIntyre (1972) and Blanchard (1963, 1975, 1983) and recently reconsidered by Dekker and De Leeuw (1993). Taking into account the model of Resch (1986), a breaking wave represent the most powerful generator of marine aerosols due to the very high rate of gas-bubble production and collapse. Three types of spray drops are produced: (1) 'jet drops' forming from the bubbles that are involved in the rotational motion of the wave scavenging the bulk seawater for some meters below the surface; (2) 'film drops' which are formed preferentially by the collapse of the whitecaps in front of the wave; (3) 'shearing drops' originated by strong winds (15-20 $\mathrm{m} / \mathrm{s}$ ) directly from the wave crest by the friction force of the high speed wind. This type of drop represents, for the most part, giant aerosol particles which therefore have a short life even in very strong winds.

\subsection{The adsorption process}

The adsorption mechanism on bubbles is well known and has been carefully examined by MacIntyre (1972) and Blanchard $(1963,1975)$ for applications to the marine environment. Although it has been known for many years that natural sea foams concentrate organic matter, (Skopincev, 1938), the effect of the foam column continuously originating in a breaking wave has not been seriously considered up to now.

In rough sea conditions, in the presence of surface active matter, the surfactants adsorption process at the air-sea interface is increased. From a general point of view, a breaking wave is not only an aerosol generator, but also a 'surfactant pumping system' that can be somewhat compared, to a 'flickering air-water adsorption bed'. The large coverage of whitecaps, acting as a high number of foam columns and running in the wind direction, produces an increase of surfactants concentration, not only at the sea surface, but even after some time in the subsurface involved in the wave motion. This concentration increase can reach some order of magnitude greater than the surfactant concentration usually present in calm sea conditions. The process itself is dependent on the duration and intensity of the sea coverage by whitecaps.

\subsection{The adsorption model for marine aerosol}

In these weather conditions the adsorption process on the spray drops surface reaches saturation. In particular this occurs for those film drops, which 
originate mainly by the foam columns, and which are continuously formed in front to the breaking wave. For soluble surfactants this happens particularly on the smallest aerosol particles. As a consequence, on the surface of all spray drops smaller than $10 \mu \mathrm{m}$ in diameter, the maximum particle dimension considered in this work, there is a saturated adsorption film of approximately the same thickness.

By considering the distribution of the surfactant organic matter (SOM) in a spray drop, we should consider both the surface adsorbed SOM as a adsorption film on the surface of the drop, and the nonsurface-adsorbed SOM, kept inside the drop with a concentration comparable to that one in seawater.

Let us consider a spray drop as a small sphere on which an adsorption film of SOM is uniformly dis- tribute. In consequence of the previous mentioned 'surface concentration wave effect' we can assume that for the smallest size drops, the film is distributed according to the saturation conditions, and with the same thickness for the particles of the whole dimensional range. This description is schematically shown in Fig. 1a. The volume of the surface adsorbed SOM (in a drop of radius $R$ ) is given by:

$V r=4 / 3 \pi R^{3}-4 / 3 \pi(R-\Delta r)^{3}$

where: $R=$ drop radius; $\Delta r=$ adsorption film thickness; therefore,

$V r / V=3 \Delta r / R-3 \Delta r^{2} / R^{2}+\Delta r^{3} / R^{3}$

where $V=$ volume of the whole droplet.

(a)
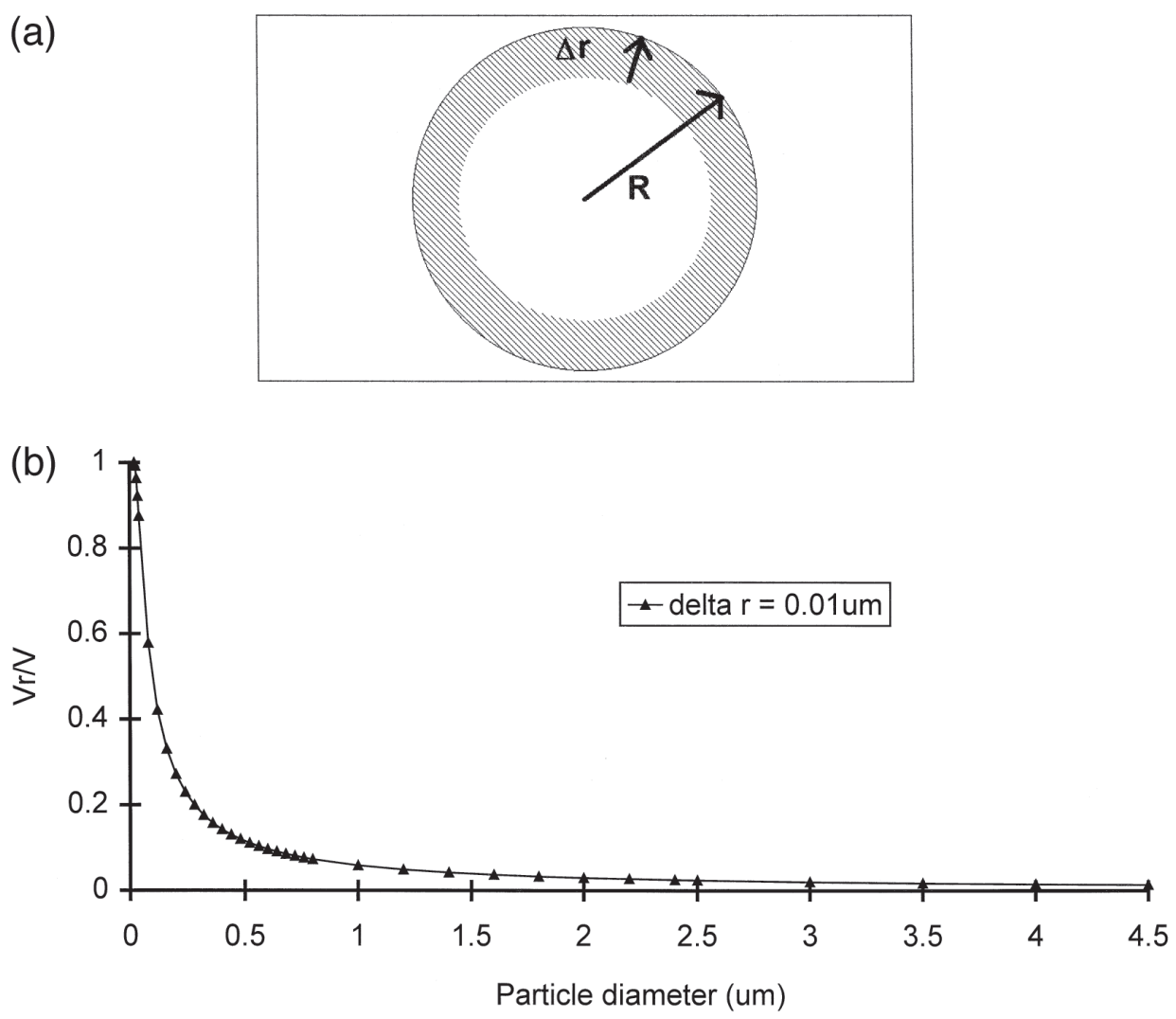

Fig. 1. (a) A schematic representation of the simplified adsorption model on a marine spray microdrop. $R=$ Microdrop radius; $\Delta r=$ Film thickness. The $\Delta r$ is constant for every particle diameter. (b) The plot of $V r / V$ vs. $R$ for $\Delta r=0.01 \mu \mathrm{m}$. The expected enrichment begin below particles diameter lower than $1 \mu \mathrm{m}$. 
Taking into account that $V r$ represents the volume of the surface adsorbed SOM with thickness $\Delta r$, and $V$ represents the volume of the whole droplet, i.e., surface adsorbed SOM and non-surface-adsorbed SOM, we can make the following consideration.

Considering for the small size drops $V$, in a first approximation, as the volume in which is contained the non-surface-adsorbed SOM (to be exact we should consider $V-V r$ ), we can deduce that the contribution of the non-surface-adsorbed SOM in comparison with the surface adsorbed SOM in $\mathrm{Vr}$ can be neglected. Thus, we can consider the whole volume $V$ represented essentially by $V r(V r \cong V)$. An equivalent but opposite deduction is valid also for the $\mathrm{Na}^{+}$ion, which is the most representative seawater element. The contribution of $\mathrm{Na}^{+}$in $\mathrm{Vr}$ can be considered zero with respect to the same contribution in $V-V r$. In fact this last quantity, as before explained, concern fundamentally the seawater.

For large size drops where $V r \ll V$ the SOM total mass contained in the microdrop, as well as the $\mathrm{Na}^{+}$ ion, is practically comparable with the seawater composition, and the contribution of the surface adsorbed SOM $(V r)$ is practically disappeared. In this case, the contribution of the $\mathrm{Na}^{+}$ion is significant because of the entirely seawater composition of the microdrop.

On the basis of the previous considerations, we can schematically summarise the following assumptions.

(1) (a) The adsorption film is saturated; (b) $\Delta r$ is constant; and (c) the SOM amount in $V r$ is predominant with respect to that one in $V-V r$.Then:

\section{$\mathrm{SOM} \propto V r$}

(2) (a) $\mathrm{Na}^{+}$is essentially present in $V-V r$; (b) $\mathrm{SOM}$ in $V-V r$ is present at the same concentration as the seawater (local source of marine aerosol).Then

$\mathrm{Na}^{+} \propto V-V r$

Furthermore, if

$V r \ll V$

then

$\mathrm{Na}^{+} \propto V$

When assumptions 1 and 2 are both true and consis- tent, then $\mathrm{Vr} / \mathrm{V}$ result proportional to the enrichment ratio (ER) of SOM. In fact the ER is here defined as:

$\mathrm{ER}=(X / \mathrm{Na})_{\text {aer }} /(X / \mathrm{Na})_{\text {sw }}$

in which $(\mathrm{X} / \mathrm{Na})_{\text {aer }}$ is the ratio for the concentrations, respectively, for component $\mathrm{X}$ and $\mathrm{Na}$ in aerosol, $(\mathrm{X} / \mathrm{Na})_{\mathrm{sw}}$ is the ratio of the concentration of the same components in seawater. The quantity $(\mathrm{X} / \mathrm{Na})_{\text {sw }}$ can be accepted constant. For this condition we can write:

$\mathrm{ER}=(\mathrm{X} / \mathrm{Na})_{\mathrm{aer}} \cdot K$

where $\mathrm{X}=\mathrm{SOM}$ and $K=$ constant $=(\mathrm{X} / \mathrm{Na})_{\mathrm{sw}}^{-1}$.

Re-writing Eq. (3) we have:

$\mathrm{ER}=(\mathrm{SOM} / \mathrm{Na})_{\mathrm{aer}} \cdot K$

which is also:

$\mathrm{ER}=V r / V \cdot K^{\prime}$

Therefore, from Eq. (2) we have:

$$
\begin{aligned}
\mathrm{ER} & =(\mathrm{SOM} / \mathrm{Na})_{\mathrm{aer}} \cdot K \\
& =\left(3 \Delta r / R-3 \Delta r^{2} / R^{2}+\Delta r^{3} / R^{3}\right) \cdot K^{\prime}
\end{aligned}
$$

The behaviour of $\mathrm{Vr} / \mathrm{V}$ with respect to the drop radius is described by an hyperbolic like function (Fig. 1b). Therefore, also the ER vs. the particles diameter can be described by a similar function:

$\mathrm{ER}=K^{\prime} \cdot\left(3 \Delta r / R-3 \Delta r^{2} / R^{2}+\Delta r^{3} / R^{3}\right)$

Hunter and Liss (1981) in their review on natural air-sea adsorption films reported that these films can reach a thickness greater than $100 \AA$, i.e., $0.01 \mu \mathrm{m}$, if they are considered as dry humic substances (HS). According to Stuermer and Harvey (1977) and Beckett (1990) HS is an important class of soluble natural surfactants $(40-60 \%)$ in the complex marine SOM mixture. For fatty acids, which are also present in SOM, although in smaller quantities, the corresponding saturated adsorption film thickness is about $25 \AA$, i.e., $2 \times 10^{-3} \mu \mathrm{m}$ as specifically measured by Gabrielli et al. (1989) for the stearic acid salts. It can be deduced from the above model that, when the film thickness is of the same order as the drop radius $R$, the microdrops become particles of a completely different composition in respect to that of seawater, i.e., essentially constituted by SOM, together with all those components that interact with SOM. This condition is well evidenced also from Fig. 1b that shows that for a drop with a radius of $0.01 \mu \mathrm{m}$, considering 
the experimental values for HS film thickness reported by Hunter and Liss (1981), the spherical particle could be completely constituted of SOM. It should be pointed out that SOM does not consist of one component, but of a complex mixture of products that differ not only in molecular weight but also in their surface activity and their ability to interact with other components. Therefore, agreement of the experimental data with the behaviour predicted by SDAM would only be expected on a qualitative basis. In addition this model, on a rigorous basis, is only valid for marine aerosol constituted of microdrops. For solid marine aerosol particles (i.e., after the water evaporation from the microdrops) a similar behaviour should be expected shifted to lowest dimensional range of the particles.

\section{Experimental}

\subsection{Sampling sites}

\subsubsection{Marine surface water and aerosol}

We selected a coastal site where a pronounced surfactant concentration increase due to rough sea conditions and inland winds were likely to take place, namely the marine coast near the Interuniversity Marine Biology and Applied Ecology Center 'Guido Bacci' in Leghorn (Tyrrhenian Sea). Notwithstanding the vicinity of the Leghorn harbour and the intense traffic of ships, the quality of the surface marine water, under calm sea conditions, appeared good and therefore, the concentration of synthetic pollutant surfactants was very low. In addition the marine aerosol, sampled for high inland winds, was not appreciably influenced by local pollution sources. Another favourable aspect was the facilities offered by the center.

\subsubsection{Clouds}

The sampling of submicron size aerosol particles requires an altitude at least $1000 \mathrm{~m}$ above sea level. Clouds could be considered a good matrix for these particles. Therefore, we selected in the Pratomagno mountains, about $100 \mathrm{~km}$ far from Tyrrhenian sea coast as a sampling station. This station was located at the Vallombrosa Arboretum. Particular care was used to select clouds of marine origin. Marine clouds, originating near the coast, in western winds at a speed $>10 \mathrm{~m} / \mathrm{s}$, rapidly reach the sampling site. Under these conditions the presence of local manmade aerosols is appreciably reduced. The wind speed and the direction were measured at the Leghorn meteorological marine station and at a meteorological station in Florence. Marine clouds at about $900 \mathrm{~m}$ above sea level in weather conditions producing large whitecaps were selected.

\subsection{Sampling techniques and sample treatment}

\subsubsection{Surface marine water}

For calm sea conditions a submersible Teflon pump with silicone pipes similar to that previously described (Loglio et al., 1989a,b) was used. For rough sea conditions a $5 \mathrm{dm}^{3}$ polyethylene bottle with a large mouth held by a nylon line formed a good sampling device. To increase the low concentration of surfactants in marine water and to simulate the effect of the whitecaps, the sample $\left(2200 \mathrm{~cm}^{3}\right)$ were enriched in surfactant matter by means of the non-foaming gas-bubble apparatus described below.

\subsubsection{Marine aerosol}

The proposed model (see Section 4) requires the aerosol to be sampled as marine spray. In this case, the spray micro-drops can be considered small spheres on which the film is uniformly distributed. Therefore, the sampling site must be on the breaking wave line along the coast and at low elevation (about $10 \mathrm{~m}$ above sea level). The large balcony in front of the Marine Biology Center at $9 \mathrm{~m}$ above sea level about $70 \mathrm{~m}$ from the breaking wave line was used. At wind speed of $6 \mathrm{~m} / \mathrm{s}$ and for wind direction of $185^{\circ}-270^{\circ}$, no perturbations in the air flux were found caused by the building with respect to that flux recorded with another anemometer on the roof of the building where all other meteorological sensors were situated.

The sampling device was a High Volume Andersen 1200 (Size Selected Inlet) fitted with a Sierra 235 cascade impactor (with five stages). The pumping flow rate (about $68 \mathrm{~m}^{3} / \mathrm{h}$ ) was set by the factory to select the aerosol particles according to the following aerodynamic diameters: 7.2, 3, 1.5, 0.95 and $0.49 \mu \mathrm{m}$. A final quartz fibre filter (Whatman) collected the smallest particles $(<0.49 \mu \mathrm{m})$. Alu- 
minium membranes were used to recover the water organic soluble fraction. The aerosol sampling event was controlled by a meteorological trigger (Schiavuta et al., 1992) which activated the sampler device only for western $\left(185^{\circ}-270^{\circ}\right)$ inland winds higher than 6 $\mathrm{m} / \mathrm{s}$ and after $0.5 \mathrm{~h}$ in these meteorological conditions. The sampling operation was also automatically interrupted during precipitation. Temperatures below $15^{\circ} \mathrm{C}$ and relative humidity higher than $85 \%$ were chosen to ensure that the sampled aerosol particles were for the most part microdrops. Failing these stated conditions, the sampling operations were stopped, and reactivated only after $0.5 \mathrm{~h}$ of the required conditions. As a first indicative aerosol sample, representing several events, a $13000 \mathrm{~m}^{3}$ sample was collected. The sampling period lasted from 1 December 1992 to the end of February 1993. The collection of such a large sample also reduce all analytical errors and uncertainties related to the blanks for the various components studied.

The extraction of water soluble components was performed on aerosol samples on the aluminium membranes, immediately after removal from the cascade impactor. Each membrane was treated with about $50 \mathrm{~cm}^{3}$ of ultra-pure water in a Pyrex glass beaker. All operations were done under laminar flux of highly filtered air. The extracted liquids were filtered with $0.45 \mu \mathrm{m}$ Nuclepore membranes. Each membrane extract was divided in to three sub-samples and analysed as described below. The same procedure was used for the final quartz fibre filter with the only difference that the extraction was repeated twice $\left(50 \mathrm{~cm}^{3}\right.$ for each extraction) and the resulting extracts were combined.

\subsubsection{Clouds}

An MTX CNB1000 apparatus was used for clouds sampling (Fuzzi et al., 1996). The sampling technique is based on Teflon wires of cloud or fog drops transported in a constant air current by a high volume pumping device. The water drops were collected in a polyethylene bottle. The sampling system was activated by a light diffusion signal given by a laser flash system and another sensor immediately stopped the sampling operation in presence of rain. A computerised system established sampling conditions for specific cloud and fog densities. We collected integrated samples, representing many events, to have a greater volume of condensed cloud water. All sampling events and the corresponding air volume sampled were recorded. The total selected air volumes for each sample varied from 300 to 3000 $\mathrm{m}^{3}$. The collected water from the cloud condensate was about $0.1-1.0 \mathrm{dm}^{3}$ for each sample and was the result of many cloud events that were singularly recorded. The sampling weather conditions were selected with the same limited conditions applied for the marine aerosol. The Teflon wire frames of the sampling apparatus and the surface of air path in the instrument were carefully washed with a non ionic surfactant Extran R AP13 1\% solution in pure distilled water and then well-rinsed three times with ultra pure distilled water before each set of sampling operations. The collected cloud water was filtered on $0.45 \mu \mathrm{m}$ Nuclepore membranes and stored at $4^{\circ} \mathrm{C}$ until analysis.

\subsubsection{Laboratory apparatus and techniques}

3.2.4.1. Non-foaming gas-bubble enrichment. The apparatus used has been previously described by Loglio et al. (1981). Hydrodynamic trap, enables an extraction better than $95 \%$ for surfactants concentration below $10^{-2} \mathrm{ppm}$ can be reached in a volume 200 times lower than the original sample. It should be noted that in presence of colloidal and particulated matter, some partition phenomena take place, and the theoretical extraction power of the process is lowered.

3.2.4.2. Generator apparatus for single jet drops of defined diameter. The apparatus is similar to that used by Sakay (1989). In our case single bubbles of a specific diameter $(0.3 \mathrm{~mm})$ were obtained by selecting a capillary (Blanchard and Syzdek, 1977) of internal column diameter $6 \mathrm{~mm}$ and the rising path of nitrogen bubbles was about $1.4 \mathrm{~m}$. This length was chosen because previous experiments (Loglio et al., 1985) showed that this was sufficient to reach saturation in the adsorption film on nitrogen bubbles of about $2 \mathrm{~mm}$ in diameter for marine water sampled in calm sea conditions. This length represented approximately the shortest path of the bubbles trapped in the bulk marine water during the rotational motion of a breaking wave. The first jet drops resulted in 
aerosols about one tenth in diameter (Blanchard, 1963) of the bubbles.

\subsubsection{Analytical techniques}

3.2.5.1. Water and aerosol. The soluble alkali and alkali earth ionic species were detected with a Dionex DX100 ion chromatograph with CS12 columns. The same apparatus with AS4A columns was used to detect some anionic species $\left(\mathrm{Cl}^{-}, \mathrm{SO}^{-}\right)$. A Perkin Elmer LS50B Luminescence Spectrometer was used to scan fluorescence spectra. We performed both emission (excitation wavelength $308 \mathrm{~nm}$, emission wavelength 320-550 nm) and synchronous scan spectra. The aerosol samples were previously filtered ( $0.45 \mu \mathrm{m}$ pore size). The synchronous scan spectra were scanned varying both the emission and the excitation wavelength, keeping the difference between them $20 \mathrm{~nm}$ (Senesi, 1990). From the emission spectra we calculated the maximum normalised fluorescence intensity (In) defined as:

In $=I_{\max } / I_{\text {Raman }} \times 100$

in which $I_{\max }$ is the maximum fluorescence intensity of the HS band $(320-550 \mathrm{~nm})$ and $I_{\text {Raman }}$ is the maximum intensity of the Raman peak of water. In our spectra the maximum was at $440-460 \mathrm{~nm}$. This band is characteristic of HS. The maximum of fluorescence intensity given by this fluorescent surfactant organic matter (SFOM). In is a quantity defined in arbitrary units and require a calibration procedure (Cini et al., 1994). In was used here as an index of the natural SOM concentration. This assumption implies that the In response should be proportional to the SFOM concentration, i.e., that the SFOM mixture and particularly the mean molecular weight of the humic matter which is the most abundant component do not change too much with respect to the aerosol particle dimension.

The concentration of the anionic synthetic surfactants (in $\mathrm{mg} / \mathrm{dm}^{3}$ ) detected as methylene-blue active substances (MBAS) (Longwell and Maniece, 1955) was used as an index of the organic pollutants in seawater. It should be remembered that only the soluble components (organic and inorganic) of the aerosol and of marine water were here considered, and the soluble fraction refers to the solution passed through a Nuclepore filter with pore diameter 0.45 $\mu \mathrm{m}$.
The detection of the $\mathrm{Pb}, \mathrm{Co}, \mathrm{Cd}, \mathrm{Fe}, \mathrm{Mn}$ and $\mathrm{Al}$ were done by means of the absorption atomic spectroscopy. A Perkin Elmer mod. 2380 with graphite furnace was used. Blank measurements were taken on the membranes and final quartz fibre filter repeating all operations used for the tested samples. In the collected aerosol samples, the poorest results for the $\mathrm{Na}$ ion were obtained for the final quartz filter. For these samples the Na blank value accounted for about $10 \%$ of the total $\mathrm{Na}$ detected values. On the aluminium membrane the $\mathrm{Na}$ blank and those of all other elements studied resulted in lower than 3\% of the total amount of each element (as soluble components). The maximum error for the ionic chromatographic data was lower than $5 \%$ in every case. For the adsorption spectroscopy data the analytical errors varied with the various components. The maximum error was about $10 \%$.

3.2.5.2. Clouds. Ion chromatography, and atomic absorption spectroscopy and fluorescence spectroscopy apparatus were the same as previously described. MBAS were again used as index of a measure of the organic surfactant pollutant and was also detected after selective enrichment of the sample with the non-foaming gas-bubble enrichment process. To improve the accuracy and the detection limits of MBAS in some case a preliminary quantitative enrichment of MBAS was performed by means the non-foaming gas-bubble enrichment process (Loglio et al., 1981).

\section{Results and discussion}

\subsection{The surface wave concentration effect}

In a previous work we (Loglio et al., 1985) reported that the surfactant matter in marine aerosol changes with time even at constant fast wind speed and direction. This fact suggest that the SOM concentration at the marine surface also changes. Data collected along the Tyrrhenian coast (S. RossorePisa) (Loglio et al., 1986) seems to confirm this phenomenon but the vicinity of the estuarine plume of Arno river to the sampling sites makes it very likely that the changes are due to variations in 
Table 1

MBAS and SFOM (given as In) concentrations and ER for selected seawater samples in calm and rough sea conditions

\begin{tabular}{llllll}
\hline $\begin{array}{l}\text { Time } \\
\mathrm{mm} / \mathrm{dd} / \mathrm{yy}\end{array}$ & $\begin{array}{l}\text { Sea } \\
\text { condition }\end{array}$ & $\begin{array}{l}\text { MBAS } \\
\pm 5 \%\end{array}$ & $\mathrm{ER}_{\mathrm{MBAS}}$ & $\mathrm{In} \pm 7 \%$ & $\mathrm{ER}_{\text {In }}$ \\
\hline $02 / 28 / 90$ & calm & 0.005 & & & \\
$03 / 03 / 90$ & rough & 0.1 & 20 & & \\
$09 / 25 / 92$ & calm & 0.009 & & & \\
$10 / 20 / 92$ & rough & 0.8 & 88 & & \\
$(09: 30)$ & & & & & \\
$10 / 20 / 92$ & rough & 0.5 & 55 & & \\
$(16: 30)$ & & & & 75.1 & \\
$03 / 15 / 93$ & rough & & & & 11 \\
$04 / 10 / 93$ & calm & & & 6.8 & \\
\end{tabular}

The MBAS concentrations are expressed in $\mathrm{mg} / \mathrm{dm}^{3}$

In $=I_{\max } / I_{\text {Raman }} \times 100$ in which $I_{\max }$ is the maximum fluorescence intensity of HS band $(320-550 \mathrm{~nm})$ and $I_{\text {Raman }}$ is the maximum intensity of the Raman peak of water.

$\mathrm{ER}_{\mathrm{MBAS}}=\mathrm{MBAS}_{\text {rough sea }} / \mathrm{MBAS}_{\text {calm sea }}$

$\mathrm{ER}_{\mathrm{In}}=\mathrm{In}_{\text {rough sea }} / \mathrm{In}_{\text {calm sea }}$.

Each sample consisted of five subsamples.

The reported data are the mean value of each sample.

surface water composition rather than to the surface wave concentration effect. Therefore, the experiment was repeated at the Leghorn sampling station and the new results are reported here. The characteristics of the sampling site are very different than S. Rossore, in particular the Leghorn samples were not affected by the large MBAS material input from the coast. Here we considered the MBAS as tracer of surfactants and pollutants. The non-foaming gas-bubble enrichment treatment on the samples examined was useful to concentrate and to detect MBAS traces. The results are summarised in Table 1. The fluorescence enrichment of SFOM was also studied in this experiment.

Each reported value is the mean of five water surface samples which were taken for each group over brief periods of times. A well-defined increase occurs from calm to rough sea conditions notwithstanding the very different coastal conditions with respect to the previous experiment. As expected there was a variation, at constant wind speed and direction, of MBAS in the presence of a constant large whitecap coverage. These data are in agreement with those previously collected (Loglio et al., 1986) and support the 'surface concentration wave effect' which is important for SDAM validity.

\subsection{Enrichment of SOM in the smaller aerosol parti- cles}

Table 2 reports the In values vs. the particle diameter of the marine aerosol sample. In can be considered proportional to the concentration of SFOM (Cini et al., 1993) which is the most important fraction of soluble SOM (Hunter and Liss, 1981), and therefore a good tracer. The largest quantities of SFOM can be detected in the smallest aerosol particles in agreement with the physical adsorption law.

To better test the adsorption model the ER was considered. The reported values can be influenced by some factors: (1) Difficulties in detecting $\mathrm{Na}$, especially in smallest particle dimension fraction; (2) the complex nature of SFOM which is restricted here to the HS can cause possible changes in the In response with respect to the true HS concentrations in the various size particle classes; (3) simplification of the calculations, which considered the maximum of the water Raman band as fixed at a definite wavelength. This has not always been experimentally verified, owing to the fact that a high background level, due to the presence of colloidal particles smaller than $0.45 \mu \mathrm{m}$, can change the form of the Raman peak slightly. Thus, the 'true' In values may be different from those evaluated considering the 'theoretical' Raman maximum.

Fig. 2 shows the ER of SFOM vs. the particle diameter together with the fitting for SDAM model taking $\Delta r=0.01 \mu \mathrm{m}$. A fitting procedure require also that the smallest dimensional range below 0.49 $\mu \mathrm{m}$ should be better defined. Therefore, in the reported fitting, we chose the mean diameter of 0.1 $\mu \mathrm{m}$ on the basis of the data taken from a recent field experiment (Despiau et al., 1996) which reports the dimensional distribution of fine particles aerosol attributed to marine origin. An hyperbolic-like trend is shown although the In value referred to the $7 \mu \mathrm{m}$ particles appear larger than expected. This behaviour could be due to the presence of HS colloidal micelles

Table 2

Normalised fluorescence values (In see text) vs. the particle diameter (in $\mu \mathrm{m}$ ) of the marine aerosol sample

\begin{tabular}{lllllll}
\hline $\begin{array}{l}\text { Particle } \\
\text { Diameter }\end{array}$ & 7.2 & 3 & 1.5 & 0.95 & 0.49 & $<0.49$ \\
\hline In & 51.51 & 142.01 & 96.43 & 238.95 & 578.86 & 1122.40
\end{tabular}




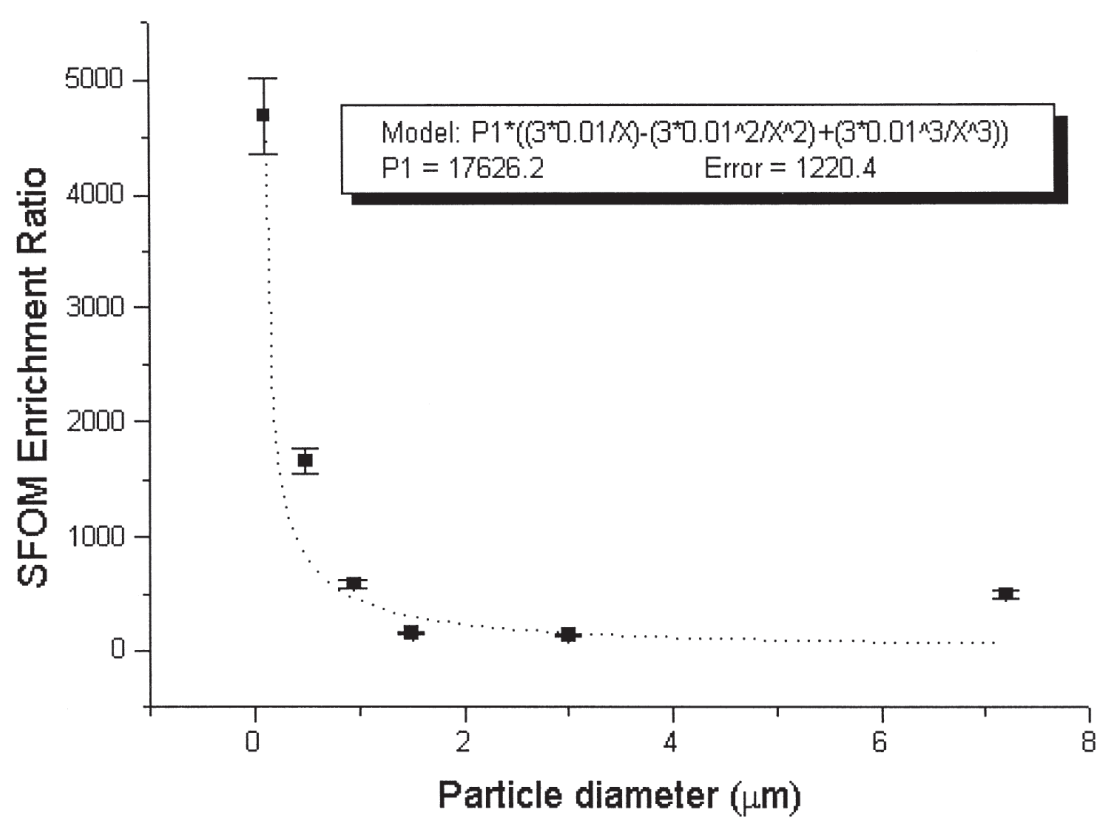

Fig. 2. Plot of experimental SFOM enrichment ratio vs. particle diameter for marine aerosol. The vertical bars represent the maximum error in ER. The interlined curve represent the fitting with $\Delta r=0.01 \mu \mathrm{m}$ and $0.1 \mu \mathrm{m}$ for the smallest class of particles. The evaluation of the constant $K^{\prime}$ and the corresponding error are also reported.

$(<0.45 \mu \mathrm{m})$ in the largest particles (Blanchard, 1975). It should be noted that each experiment point corresponds to an integrated sample of twelve storm events. Each storm event is comprehensive of 6-7 sampling operations selected as previously described.

Taking into account all the mentioned limitations which affect the ER SFOM values, and the large error related to $K^{\prime}$, it is relevant that the experimental increase of ER appear evident for the classes of particles $<1 \mu \mathrm{m}$, just as predicted by SDAM (Fig. $1 b)$.

As previously cited, the SFOM behaviour can be considered as a tracer to evaluate the distribution of $\mathrm{SOM}$ in the size spectrum of marine aerosols. Therefore, it is to be expected that all those components which interact with SOM should show similar behaviour with only slight changes.

Owing to the high number of functional groups present in the macromolecular structure of HS, many types of interactions are possible with heavy metals ions (Mantoura, 1981), and with various organic compounds (especially synthetics) with pollutant properties (MacCarthy and Suffet, 1989; Leehneer et al., 1989). As noted by Hunter and Liss (1981), even fatty acids and lipids constitute a part of the SOM present in marine microlayer. They are able to form soaps with natural ions. These soaps, for the bivalent ions as $\mathrm{Ca}$ and heavy metals in most cases, form solid condensed films, i.e., saturated films.

\subsection{Heavy metals and aluminium}

One of the most impressive experiments which proved the ability of marine SOM to interact with

Table 3

Selected element concentrations in natural aerosol

\begin{tabular}{lllllrr}
\hline Metal & \multicolumn{6}{l}{ Particle diameter } \\
\cline { 2 - 7 } & 7.2 & 3 & 1.5 & 0.95 & 0.49 & $<0.49$ \\
\hline $\mathrm{Cu}$ & 0.22 & 0.07 & 0.03 & 0.03 & 0.04 & 1.24 \\
$\mathrm{Cd}$ & 0.00 & 0.01 & 0.00 & 0.00 & 0.01 & 0.11 \\
$\mathrm{~Pb}$ & 0.02 & 0.03 & 0.03 & 0.02 & 0.10 & 0.14 \\
$\mathrm{Mn}$ & 0.10 & 0.13 & 0.08 & 0.30 & 0.17 & 0.58 \\
$\mathrm{Fe}$ & 0.62 & 0.35 & 0.34 & 0.34 & 2.02 & 6.91 \\
$\mathrm{Al}$ & 0.85 & 0.87 & 0.74 & 1.25 & 10.49 & 25.91 \\
\hline
\end{tabular}

Selected elements concentrations (expressed in $\mathrm{ng} / \mathrm{m}^{3}$ ) for aerosol having various particle diameters (in $\mu \mathrm{m}$ ).

Each value is the mean value of a duplicated analysis.

The experimental error was $\pm 5 \%$. 
heavy metals ions was reported by Piotrowicz et al. (1979) and Weisel et al. (1984) and recently cited by Chester (1990). By means of the bubble interfacial microlayer sampler (BIMS), artificial aerosol were produced directly in the sea. The results showed that the heavy metals, enriched in the marine microlayer,
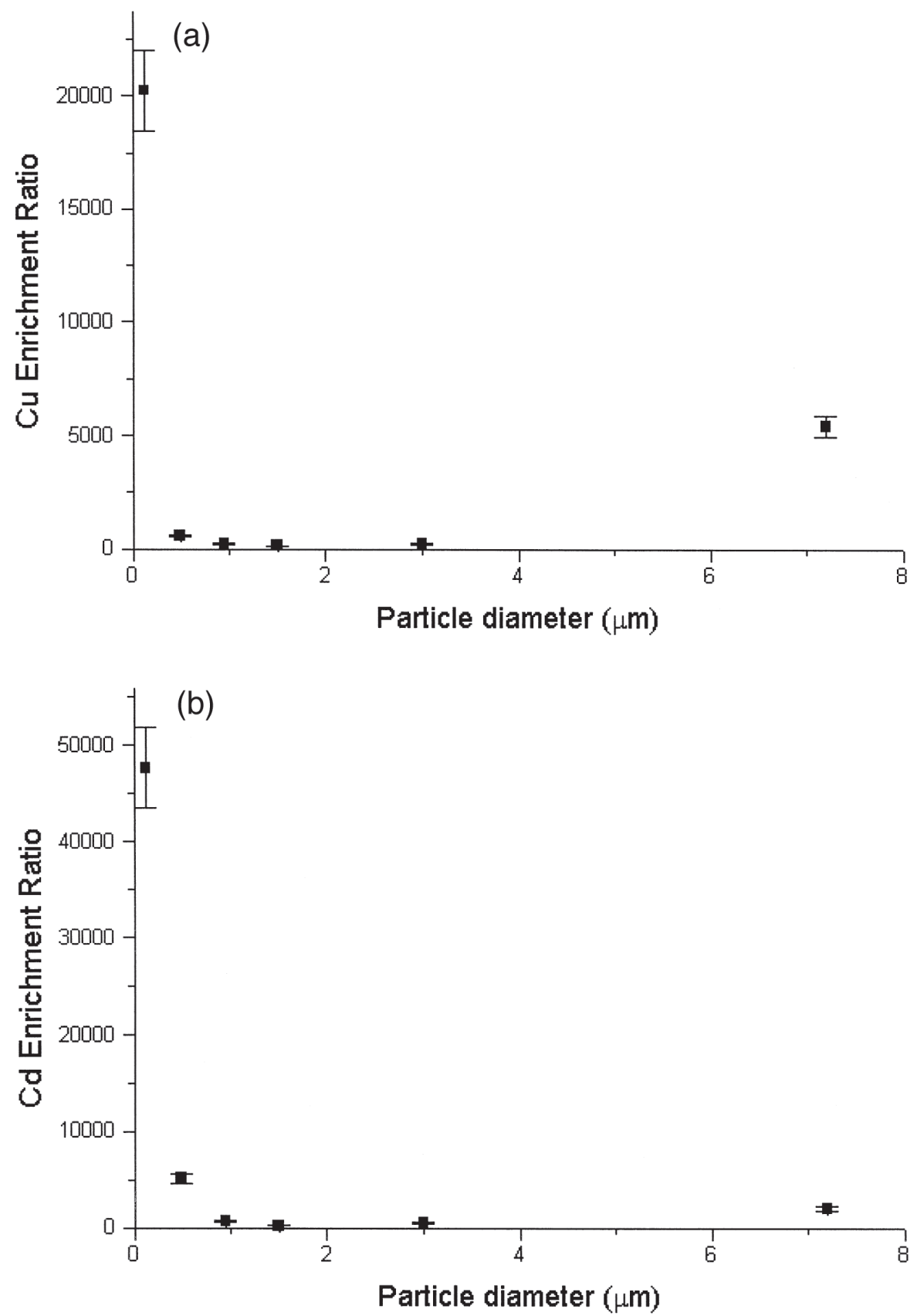

Fig. 3. Plot of the experimental enrichment ratios of selected elements vs. particle diameter for marine aerosol. These plots refer respectively to: (a) to $\mathrm{Cu}$, (b) to $\mathrm{Cd}$ and (c) to $\mathrm{Pb}$, (d) to $\mathrm{Mn}$, (e) to $\mathrm{Fe}$, (f) to Al. For the formula of enrichment factor see text. 

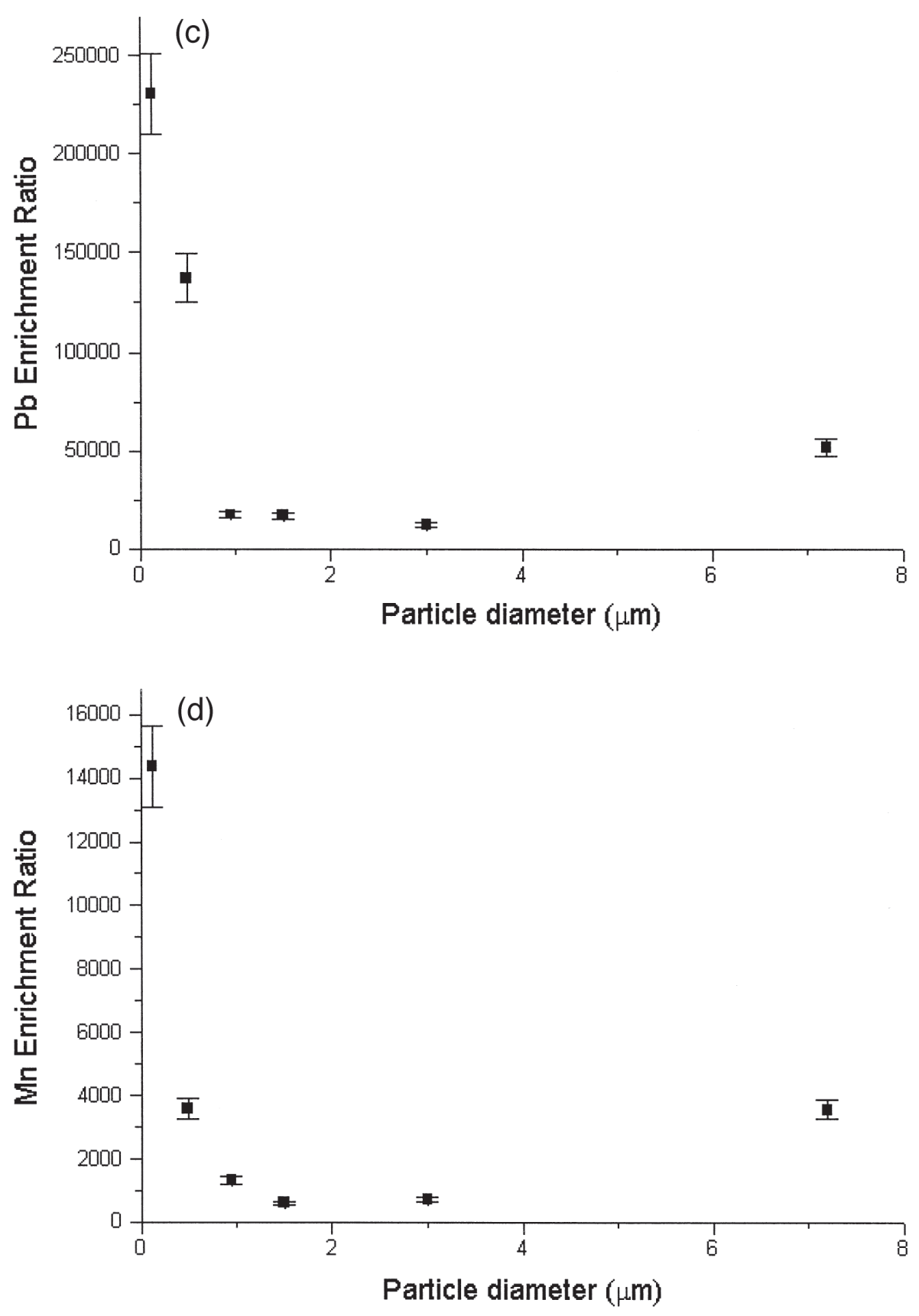

Fig. 3 (continued).

where also transferred and enriched in the marine spray, confirming their interaction with biogenic surfactant matter.
On the basis of these results, it is interesting to examine the result obtained for heavy metals in this experiment. In Table 3 the concentrations in $\mathrm{ng} / \mathrm{m}^{3}$ 

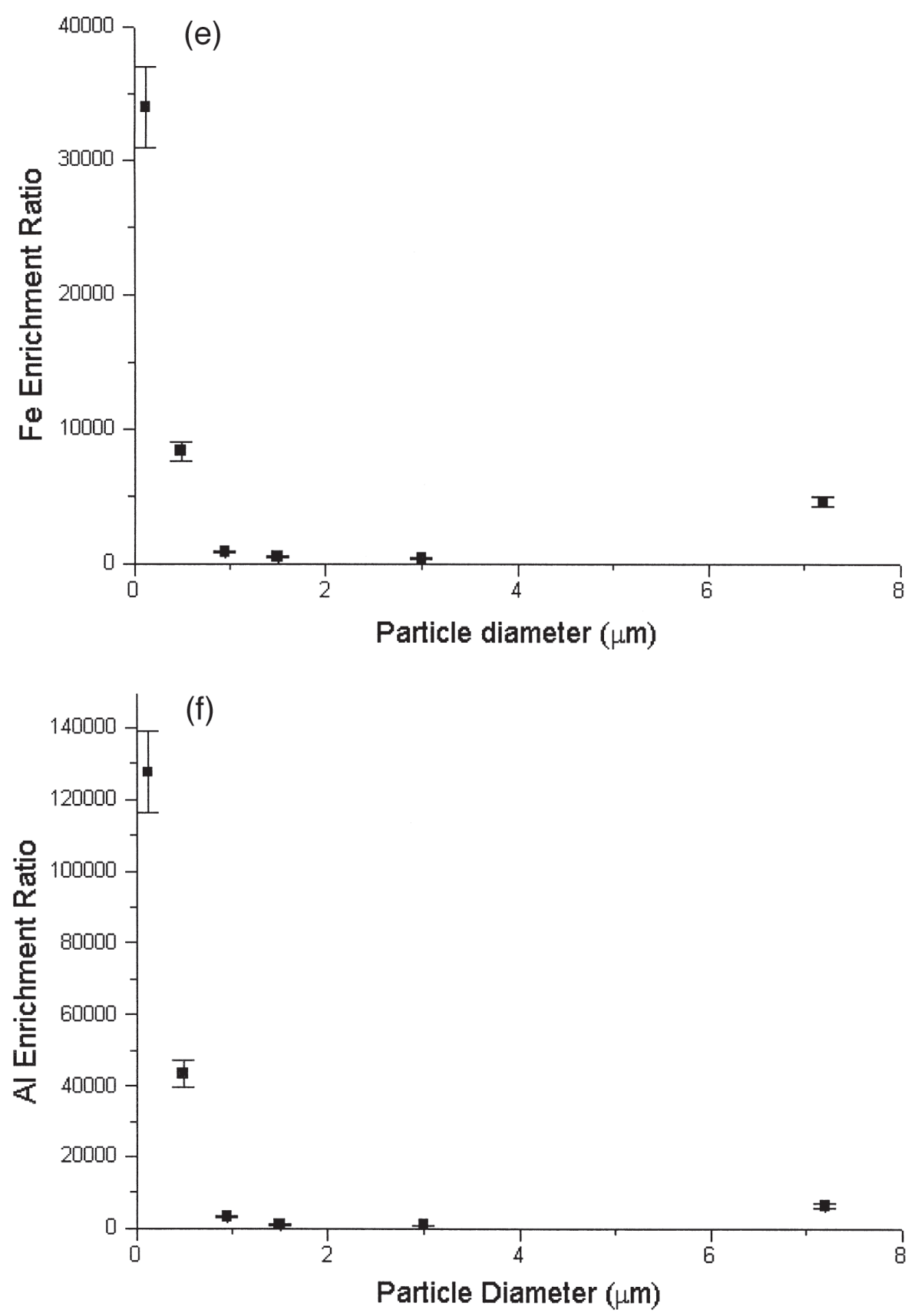

Fig. 3 (continued).

for $\mathrm{Cu}, \mathrm{Cd}, \mathrm{Pb}, \mathrm{Mn}, \mathrm{Fe}$, and $\mathrm{Al}$ are reported. Fig. $3 \mathrm{a}-\mathrm{f}$ shown the corresponding ER vs. the particle diameter graphs. The first observation is that ER increases rapidly for particles smaller than $1 \mu \mathrm{m}$ diameter, with a behaviour similar to that of the SFOM. The ER values vary from 14000 for Mn to 250000 for $\mathrm{Pb}$. The latter value is greater than the one generally reported in the literature for marine 
aerosol, but similar to that reported for marine microlayers and foams (Szekielda et al., 1972). This behaviour can be attributed to the different binding capacity of various components in the SFOM (Mantoura, 1981). In addition for most of the studied elements, the ER values are higher for the $7 \mu \mathrm{m}$ fraction with respect to what is expected from the model, i.e., they show the same anomaly of SFOM enrichment. Although a definitive explanation is not possible at present, this similarity could link the behaviour of SFOM with the other elements according to Fig. 2.

Comparing our results with those of Barker and Zetlin (1972) for the compounds considered in both papers, we note that the ER values in our experiments are higher. It should be noted that the values in Barker and Zetlin's paper refer to dry particles; while our result refer to wet particles or more specifically to the spray particles. A larger content of $\mathrm{Na}$ is therefore found in the dry particles with consequently lower ER values. A comparison of our results with those obtained in BIMS experiments by Weisel et al. (1984) is not possible since the BIMS data refer only to the mean diameter of aerosol particles.

\section{4. $\mathrm{K}, \mathrm{Mg}$ and $\mathrm{Ca}$}

$\mathrm{K}, \mathrm{Mg}$ and $\mathrm{Ca}$ are of particular interest because although the elements are not pollutants, together with $\mathrm{Na}$ they represent a marine origin signature in aerosol studies. On the other hand, the $\mathrm{K}$ and $\mathrm{Ca}$ non-sea-salt excess reported by many studies (see Hoffman et al., 1974, 1980; Chesselet et al., 1972) is a matter for discussion, especially the $\mathrm{Ca}$ excess mainly attributed to a crustal contribute. The non marine origin hypothesis for $\mathrm{K}$ and $\mathrm{Ca}$ excess has been reinforced by the accurate experiment of Hoffman and Duce (1977) in order to establish the nature of enrichment in marine aerosol of these elements. Hoffman and Duce concluded that $\mathrm{Ca}$ and $\mathrm{K}$ excess in marine aerosol cannot be due to their interaction with marine SOM.

We therefore analysed $\mathrm{K}$ and $\mathrm{Ca}$ enrichment using a new experimental approach. The experiment was carried out on seawater sampled near the marine station in Leghorn. The seawater sample was submitted to the non-foaming gas-bubble enrichment proce- dure (Loglio et al., 1981) to simulate SFOM enrichment in rough sea conditions. The nominal enrichment expected for surfactant fluorescent organic matter (SFOM) was reached by adjusting the volume ratio of the enriched and non-treated fractions for similar SFOM concentration to that found for high whitecap coverage. Table 4 reports three typical sets of results for:

1. artificial seawater after high performance purification with non-foaming gas-bubble enrichment treatment (Loglio et al., 1981);

2. natural seawater directly submitted to the aerosolization procedure;

3. the same water previously enriched by means of the non-foaming gas-bubble enrichment treatment (Loglio et al., 1981) and then aerosolised.

The ion species concentrations were detected by ion chromatography. Each set of measurements refers to three subsamples. Table 4 shows the mean values with the maximum relative error and from these data an enrichment for $\mathrm{K}$ and $\mathrm{Ca}$ can be seen; there is no practical enrichment for $\mathrm{Mg}$. Therefore, the experiment appears to support the marine origin of $\mathrm{K}$ and $\mathrm{Ca}$ excess in our field data on marine aerosols.

Fig. $4 a, b$ and $c$ show the plots of ER vs. the particle diameter for $\mathrm{K}, \mathrm{Ca}$ and $\mathrm{Mg}$ relevant to the field experiment. It is interesting to note that the order of magnitude of K-ER and Ca-ER, found for the smallest particles in this marine aerosol, agrees with the literature. On the other hand the K-ER and Ca-ER are much lower than the ER of heavy metals. Assuming the hypothesis of the marine origin of $\mathrm{K}$ and $\mathrm{Ca}$ is correct, these preliminary data provide an explanation of the difference between the ER of

Table 4

Enrichment ratios of $\mathrm{K}, \mathrm{Ca}$ and $\mathrm{Mg}$ in respect to $\mathrm{Na}$ in artificial aerosol

\begin{tabular}{llll}
\hline Experiment & $\mathrm{K}-\mathrm{ER} \pm 2 \%$ & $\mathrm{Ca}-\mathrm{ER} \pm 2 \%$ & $\mathrm{Mg}-\mathrm{ER} \pm 2 \%$ \\
\hline $\mathrm{a}$ & 1.02 & 1.01 & 1.01 \\
$\mathrm{~b}$ & 1.11 & 1.07 & 1.04 \\
$\mathrm{c}$ & 1.98 & 1.68 & 1.02 \\
\hline
\end{tabular}

Experiment performed on: a, artificial seawater; b, natural seawater; c, natural seawater previously enriched with natural surfactants by the gas-bubble process and then aerosolised.

In the last case the laboratory aerosol was obtained by rigorous collection of the 'top jet drops' from single bubbles.

The raising path was $1.40 \mathrm{~m}$ in natural surfactant enriched water. 
alkali and alkali earth and the ER of heavy metals. This can be due in a first instance to the very different concentration of $\mathrm{K}, \mathrm{Ca}$ and $\mathrm{Mg}$ in seawater with respect to that of the other elements and to the type of interactions taking place between these elements and SFOM. The anomalous behaviour of $\mathrm{Ca}$ -
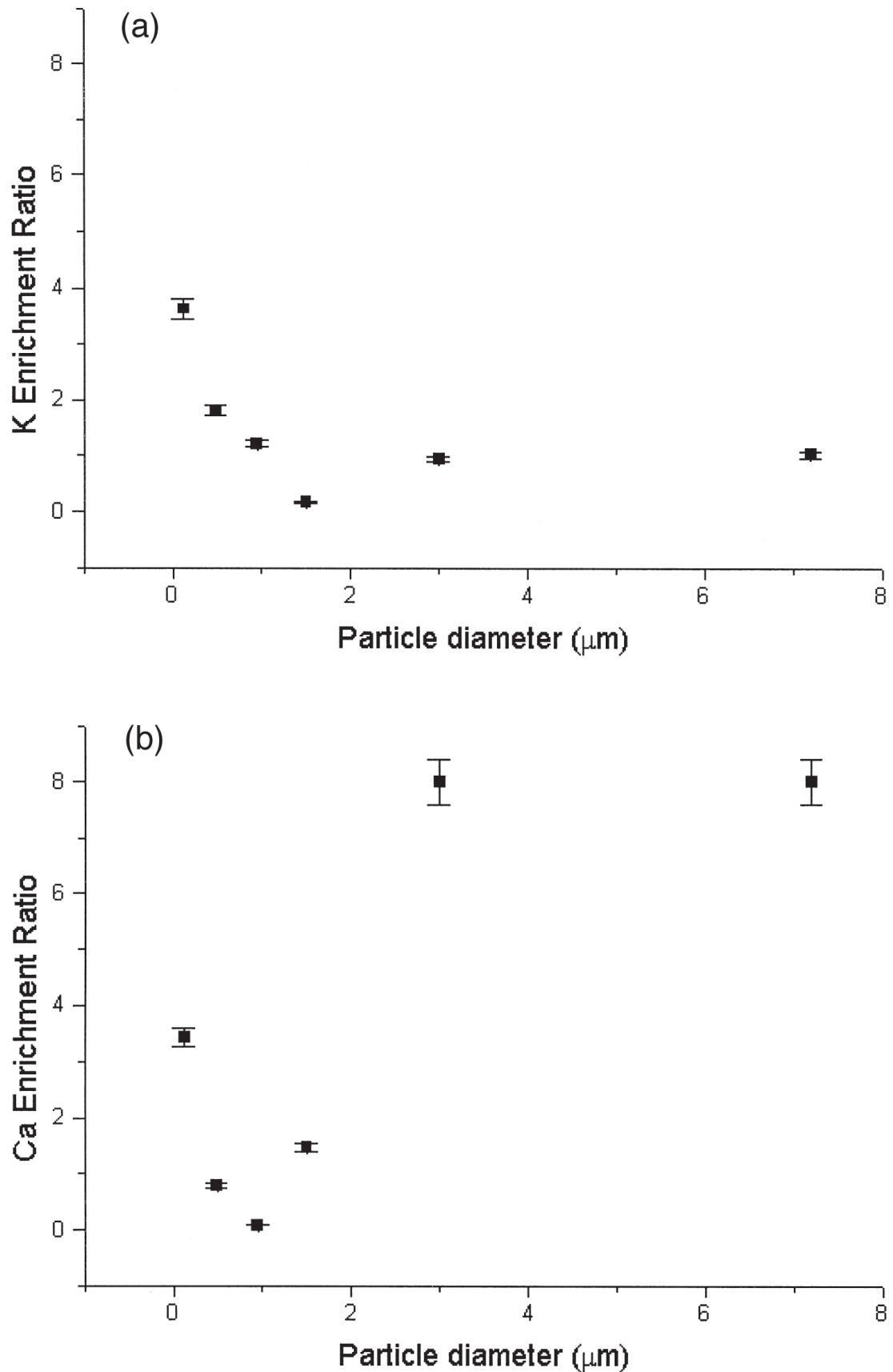

Fig. 4. Plot of the experimental enrichment ratios of selected alkali and alkali-earth elements vs. particle diameter for marine aerosol. These plots are referred respectively to: (a) to K, (b) to Ca and (c) to Mg. For the formula of enrichment factor see text. 


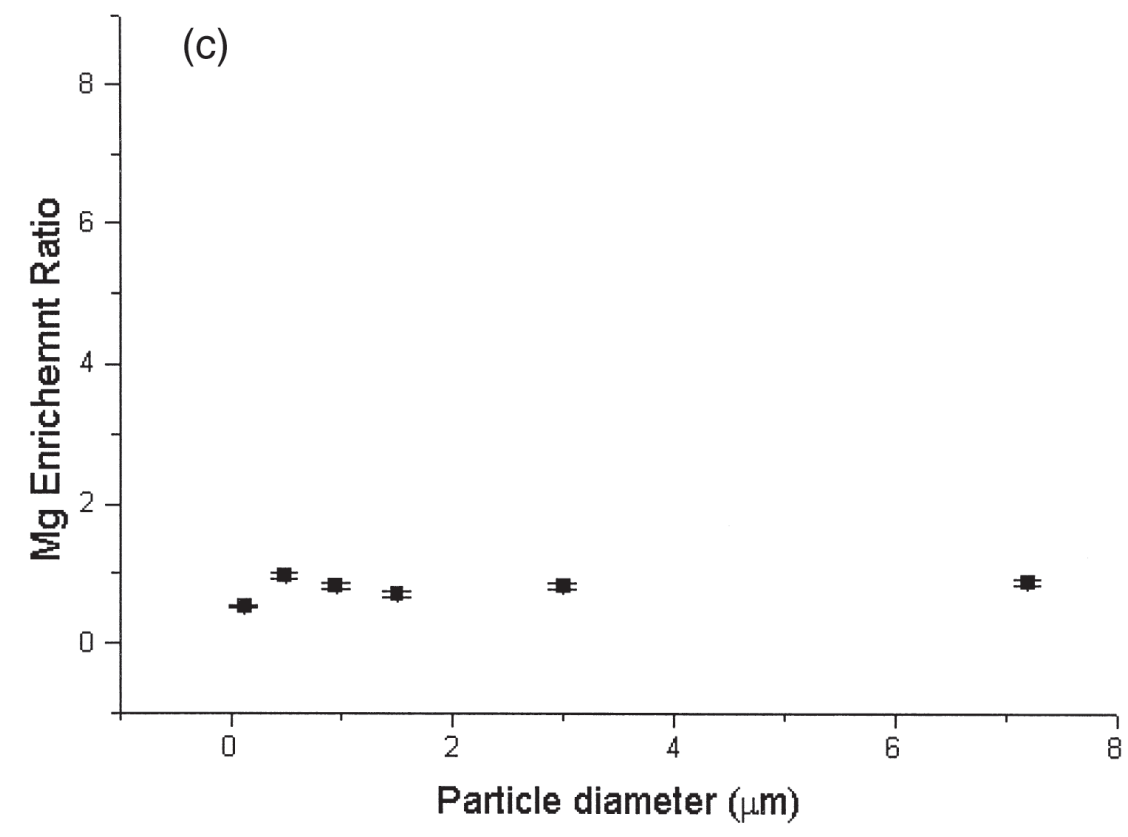

Fig. 4 (continued).

ER for the larger fractions of the aerosol sample studied could be attributed to the interaction with those marine bacterial which interact with $\mathrm{Ca}$ and which are present in marine water (Castanier et al., 1986; Rivandeneyra et al., 1994). Recent preliminary experiments (Pampaloni et al., 1997) support this hypothesis. However, this point requires more specific field experiments on the bacteria presence in the various particle size range.

\subsection{Cloud experiments}

A careful laboratory experiment of Cipriano et al. (1983) has demonstrated that particles smaller than $0.01 \mu \mathrm{m}$ can originate from a breaking wave simulated by a seawater fall. This study identified marine aerosol submicron particles in the atmosphere. These particles can act as cloud nuclei $(\mathrm{CN})$ and cloud condensation nuclei $(\mathrm{CCN})$ and indicate that marine clouds can be an excellent collector of the small particle fraction of marine aerosols. To test our adsorption model on these particles we studied the chemical composition of marine clouds at $1000 \mathrm{~m}$ above sea level and at $100 \mathrm{~km}$ from the coast.
Table 5 reports the ER for heavy metals ( $\mathrm{Al}, \mathrm{Pb}$, $\mathrm{Cu}, \mathrm{Mn}, \mathrm{Fe}, \mathrm{Cd}$ ) and the ER for alkali-alkali earth elements $(\mathrm{Ca}, \mathrm{Mg}, \mathrm{K})$, for seven cloud samples of marine origin. The $\mathrm{Na}$ concentration is assumed to be essentially of marine origin. Chlorine was not considered here because of its partial depletion in the small particles due to the $\mathrm{HNO}_{3}$ and $\mathrm{H}_{2} \mathrm{SO}_{4}$ acidity present in the clouds studied. Part of the $\mathrm{HNO}_{3}$ and $\mathrm{H}_{2} \mathrm{SO}_{4}$ can also be considered of marine origin $\left(\mathrm{H}_{2} \mathrm{SO}_{4}\right.$ for example from further oxidation of MSA). The mean value (the ratio of the concentrations expressed in $\mu \mathrm{g} / \mathrm{dm}^{3}$ ) of $\mathrm{MBAS} / \mathrm{Na}$ in marine clouds is 0.05 . This value is about the same as the corresponding ratio for marine aerosol particles smaller than $8 \mu \mathrm{m}$ found in a previous work (Cini et al., 1993). The higher value found in condensed-cloud water appears well justified by the smallest particle diameter present in clouds. The evaluation of MBAS-ER was not possible in the absence of the those MBAS concentrations for the corresponding rough sea conditions in the same period. It should be noted that although the absolute quantities of the elements considered vary greatly (by the factors of 20 to 70 ), the reported ERs for the corresponding $\mathrm{Na}$ 
Table 5

Enrichment ratios for selected elements in marine clouds sampled in Vallombrosa (1000 m above sea level)

\begin{tabular}{|c|c|c|c|c|c|c|c|c|c|}
\hline \multirow[t]{2}{*}{ Date } & \multicolumn{9}{|l|}{ Metal (ER) } \\
\hline & $\mathrm{Al}$ & $\mathrm{Pb}$ & $\mathrm{Cu}$ & $\mathrm{Mn}$ & $\mathrm{Fe}$ & $\mathrm{Cd}$ & $\mathrm{Ca}$ & $\mathrm{Mg}$ & $\mathrm{K}$ \\
\hline $10 / 11-13 / 11 / 92$ & $2.44 \mathrm{e}+05$ & $6.66 \mathrm{e}+06$ & $9.02 \mathrm{e}+04$ & $8.00 \mathrm{e}+04$ & $5.80 \mathrm{e}+04$ & $7.89 e+04$ & 9.41 & 0.90 & 6.48 \\
\hline $29 / 12 / 92-21 / 01 / 93$ & $6.18 \mathrm{e}+05$ & $2.22 \mathrm{e}+07$ & $1.24 \mathrm{e}+05$ & $2.25 \mathrm{e}+05$ & $4.61 e+05$ & $3.50 \mathrm{e}+05$ & 8.53 & 0.89 & 2.92 \\
\hline $23 / 12 / 93-12 / 01 / 94$ & $9.98 \mathrm{e}+04$ & $6.22 \mathrm{e}+06$ & $1.01 \mathrm{e}+05$ & $4.72 \mathrm{e}+04$ & $4.97 e+04$ & $6.60 \mathrm{e}+04$ & 3.72 & 0.88 & 4.45 \\
\hline $10 / 05-25 / 05 / 94$ & $2.88 \mathrm{e}+05$ & $9.77 e+06$ & $2.01 \mathrm{e}+05$ & $9.66 e+04$ & $2.34 \mathrm{e}+05$ & $2.01 \mathrm{e}+05$ & 10.10 & 1.25 & 3.63 \\
\hline $31 / 08-13 / 09 / 94$ & $2.51 \mathrm{e}+04$ & $6.19 e+05$ & $9.22 \mathrm{e}+04$ & $7.04 \mathrm{e}+04$ & $3.48 \mathrm{e}+04$ & $2.09 \mathrm{e}+06$ & 45.44 & 1.49 & 40.96 \\
\hline $21 / 10-09 / 11 / 94$ & $7.37 e+04$ & $4.10 \mathrm{e}+06$ & $3.78 \mathrm{e}+04$ & $2.33 e+04$ & $4.47 e+04$ & $2.84 \mathrm{e}+05$ & 5.25 & 0.86 & 4.29 \\
\hline $18 / 02-17 / 03 / 95$ & $1.02 \mathrm{e}+05$ & $2.69 \mathrm{e}+06$ & $4.08 \mathrm{e}+04$ & $2.49 e+04$ & $6.93 e+04$ & $8.84 \mathrm{e}+04$ & 4.61 & 0.51 & 3.16 \\
\hline
\end{tabular}

ERs are given by: $\mathrm{ER}_{\mathrm{X}}=(\mathrm{X} / \mathrm{Na})_{\text {cloud }} /(\mathrm{X} / \mathrm{Na})_{\mathrm{sw}}$ where: $\mathrm{X}_{\text {cloud }}$ is the concentration of the selected element in the cloud; $\mathrm{Na}$ cloud is the concentration of sodium in the cloud; $\mathrm{X}_{\mathrm{sw}}$ is the concentration of the selected element in seawater; $\mathrm{Na}_{\mathrm{sw}}$ is the concentration of sodium in seawater.

The experimental error was $\pm 9 \%$ referred to a duplicated analysis for each sample.

concentrations are comparable to those found in the lowest size particles in our marine aerosol samples.

Fig. 5 reports the synchronous scan fluorescence spectra for three SFOM significant samples: a typical cloud sample; a solution of the smallest particle fraction $(<0.49 \mu \mathrm{m})$ of the previously described aerosol sample (shown in Fig. 2), and a filtered marine water sample from Leghorn. A comparison of these spectra shows a similar structure of SFOM for the three samples, and therefore further supports the marine origin of cloud samples. Although the present data must be considered as preliminary the presence

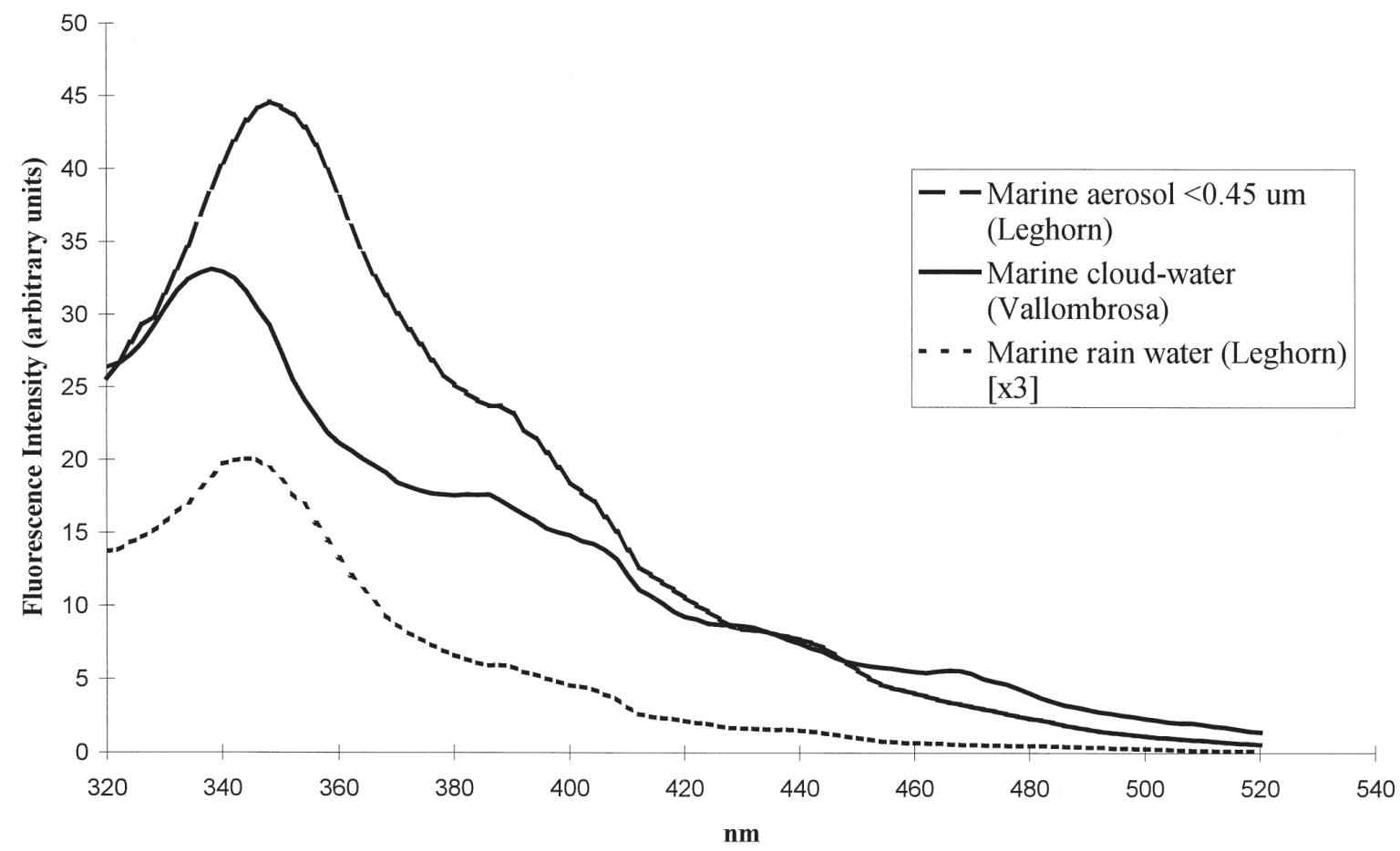

Fig. 5. Synchronous fluorescence scan spectra $(\Delta \lambda=20 \mathrm{~nm})$ of marine aerosol and marine water (Leghorn), and clouds (Vallombrosa). 
of MBAS and SFOM that are also found in the smallest particles of marine aerosol is important. It is also significant that the synchronous scan fluorescence spectra for SFOM of cloud samples as reported in Fig. 5 are very similar to the finest fraction of the marine aerosol, sampled at Leghorn station.

The data in Table 5 show that the $\mathrm{K}$ and $\mathrm{Ca}$ enrichment values in the marine cloud samples are lower by some order of magnitude than the ones for the heavy metals was also the same as in the marine aerosols. This could be a further indication of the marine origin of the elements found in our cloud samples. It is also interesting that the average $\mathrm{Ca}$ enrichment in these cloud samples is higher than that of $\mathrm{K}$, in agreement with the stronger interactions possible for this element with soluble SOM. This increase in concentration is usually associated to the crustal origin of $\mathrm{Ca}$. In our opinion it can be due essentially to fatty acids. In fact, owing to their high surface activity and low molecular weight, these are more enriched in the smallest marine aerosol particles.

Heavy elements can have crustal and urban pollution origins, but it should be kept in mind that their recycling via marine aerosols after their sea surface deposition is a more probable process, as the present laboratory and field experiments on marine aerosol show.

\section{Concluding remarks}

Although the presented data are to be considered as preliminary, they support a new approach based on the physical adsorption, (Cini and Loglio, 1997), applied to the fine particles of marine aerosol.

SDAM appears able to give a more extended explanation about the origin of a large class of fine aerosol particles which until very recently (Finlayson-Pitt and Pitts, 1997) were attributed essentially to gas-to-particle conversion or to other physicochemical processes.

According to the SDAM, the transition from saline nature for the largest particles, to an essentially organic nature, for the smallest particles, can offer an alternative explanation to the long range transport of many pollutants via marine aerosol. For these pollutants able to interact with SOM, their recycling process from marine surface to the atmosphere could occur in a much larger scale in respect to that considered up to now.

The peculiarity of the fine fraction of marine aerosol together with its ubiquitous character could constitute an additional basis in the estimation of the global changes in air quality. The presence of this fine fraction in marine clouds suggests that the study of the same microcomponents which are also collected in high altitude coastal Antarctic snow (Cini et al., 1995, 1998) could be a useful approach to reach further confirmation of SDAM general applicability.

\section{Acknowledgements}

This study was partially supported by the CNRENEL Project, 'Interaction of Energy System with Human Health and Environment' and MURST 40\% Physics Section. Many thanks to the Director of the Inter University Centre of Marine Biology and of the Municipal Aquarium of Leghorn for their hospitality and logistic assistance. We greatly thank the Director of the Experimental Institute of Silvicolture in Arezzo for his hospitality in the 'Arboreto of Vallombrosa', and the State Forestry Office of Vallombrosa for its kind help. Many thanks are also due to our technician Gabriele Orlandi for his helpful work.

\section{References}

Arimoto, R., Duce, R., Ray, B., 1989. Concentration sources and air-sea exchange of trace elements in the atmosphere over the Pacific Ocean. In: Riley, J.P. Chester, R. (Eds.), Chemical Oceanography, 10. Academic Press, London, 144 pp.

Barker, D.K., Zetlin, H., 1972. Metal-ion concentration in seasurface microlayer and size separated atmospheric aerosol samples in Hawaii. J. Geophys. Res. 77, 5076-5086.

Beckett, R. (Ed.), 1990. Surface and Colloid Chemistry in Natural Waters and Water Treatment. Plenum, New York.

Berg, W.W., Winchester, J.W., 1978. Aerosol chemistry of the marine atmosphere. In: Riley, J.P., Chester, R. (Eds.), Chemical Oceanography, 7. Academic Press, London, pp. 173-231.

Blanchard, D.C., 1963. The electrification of the atmosphere by particles from bubbles in the sea. Prog. Oceanogr. 1, 71-202.

Blanchard, D.C., 1975. Bubble scavenging and the water-to-air transfer of organic material in the sea. Adv. Chem. Ser. 145, $360-387$. 
Blanchard, D.C., 1983. The production distribution and bacterial enrichment of the sea salt aerosol in air-sea exchange of gases and particles. In: Liss, P., Stum, W. (Eds.). Reidel, Dordrecht, pp. 407-454.

Blanchard, D.C., Syzdek, L.C., 1977. Production of air bubbles of a specified size. Chem. Eng. Sci. 32 (9), 1109-1112.

Castanier, S., Maurin, A., Bianchi, A., 1986. Evolution des populations bacteriennes precipitant le carbonate avec an sans alaclinization du melien, dans le differents cas de confinement experimentel, d'eau at de sediment lagunaires mediterranee. GERBAM Deuxieme colloque internationale de bacteriologie marine. IFREMER Actes de colloques, 3, pp. 147-157.

Chesselet, R., Morelli, J., Buat-Menard, P., 1972. Variation in ionic ratios between reference seawater and marine aerosols. J. Geophys. Res. 77, 5116-5131.

Chester, R., 1990. Transport of material to the oceans: the atmospheric pathway. In: Marine Geochemistry. Unvim. Hyman, Boston, pp. 106-129.

Cini, R., Loglio, G., 1997. Adsorption and pollutants transport by marine aerosol. Mar. Pollut. Bull.

Cini, R., Oppo, C., Bellandi, S., Loglio, G., Degli Innocenti, N., Stortini, A.M., Schiavuta, E., Tesei, U., Orlandi, G., Pantani, F., 1993. Pollutant transport associated with marine aerosol In: Ciccioli, P. (Ed.), First National Symposium on 'Strategie e tecniche di monitoraggio sull'atmosfera', Rome Sept. 20-22. SCI. Proceedings, pp. 168-175 (in English).

Cini, R., Degli Innocenti, N., Loglio, G., Orlandi, G., Stortini, A.M., Tesei, U., 1994. Spectrofluorimetric evidence of the transport of marine organic matter in antartic snow via air-sea interaction. Int. J. Environ. Anal. Chem. 55, 285-295.

Cini, R., Degli Innocenti, N., Loglio, G., Oppo, C., Orlandi, G., Stortini, A.M., Tesei, U., Udisti, R., 1995. Air-sea exchange: sea-salt and organic microcomponents in Antarctic snow. Int. J. Environ. Anal. Chem. 67, 15-27.

Cini, R., Udisti, R., Piccardi, G., Loglio, G., Degli Innocenti, N., Stortini, A.M., Pampaloni, B., Tesei, U., 1998. A simple model for $\mathrm{K}$ and $\mathrm{Ca}$ enrichment interpretation in Antarctic snow. Int. J. Environ. Anal. Chem., in press.

Cipriano, R., Blanchard, D.C., Hogan, A., Lala, G., 1983. On the production of Aitken nuclei from breaking waves and their role in the atmosphere. J. Atmos. Sci. 40, 469-479.

Dekker, H., De Leeuw, G., 1993. Bubble excitation of surface waves and aerosol droplet production: a simple dynamical model. J. Geophys. Res. 98, 10223-10232.

Despiau, S., Congnec, S., Resch, F., 1996. Concentration and size distribution of aerosol particles in coastal zone. J. Aerosol Sci. 27, 403-415

Finlayson-Pitt, B.J., Pitts, J., 1997. Tropospheric air pollution ozone airborne toxics, policyclic aromatic hydrocarbons, and particles. Science 276, 1045-1052.

Fuzzi, S., Facchini, M.C., Orsi, G., Bonforte, G., Martinotti, W., Ziliani, G., Mazzali, P., Rossi, P., Natale, P., Grosa, M., Rampado, E., Vitali, P., Raffaelli, R., Azzini, G., Grotti, S., 1996. The Nevalpa Project: a regional network for fog chemical climatology over the Po valley basin. Atmospheric Environment $30,201-213$.
Gabrielli, G., Puggelli, M., Ferroni, E., Carubia, G., Pedrocchi, L., 1989. Mono and multilayers of bivalent ions stearates. Colloid and Surfaces 4, 1-13.

Hoffman, E.J., Duce, R.A., 1977. Alkali and alkaline earth metal chemistry of marine aerosols generated in the laboratory with natural seawaters. Atmospheric Environment 11, 367-372.

Hoffman, E.J., Hoffman, C.L., Duce, R.A., 1974. Chemical fractionation of alkali and alkaline earth metals in atmospheric particulate matter over the North Atlantic. J. Rech. Atmos. 8, 675-688.

Hoffman, E.J., Hoffman, C.L., Duce, R.A., 1980. Particle size dependence of alkali and alkaline earth metal enrichment in marine aerosol from Bermuda. J. Geophys. Res. 85 (C10), 5499-5502.

Hunter, K.H., Liss, P.S., 1981. Organic sea surface films. In: Duursma, E.K., Dawson, R. (Eds.), Marine Organic Chemistry. Elsevier, Amsterdam, pp. 259-298.

Leehneer, J.A., Brown, P.A., Noyes, T.I., 1989. Implications of mixture characteristic on humic substances chemistry. In: Suffet, I.H., MacCarthy, P. (Eds.), Aquatic Humic Substances. Influence on Fate and Treatment of Pollutants. Adv. Chem. Ser., 219, pp. 25-39.

Loglio, G., Tesei, U., Cellini Legittimo, P., Racanelli, E., Cini, R., 1981. Bubble extraction as an auxiliary method in the analysis of water. Ann. Chim. 71, 251-261.

Loglio, G., Tesei, U., Mori, G., Pantani, F., Cini, R., 1985. Enrichment and transport of surfactants in marine aerosol formed during particular weather conditions. Il Nuovo Cimento C 8, 704-713.

Loglio, G., Costa, M.G., Gelsomini, N., Tesei, U., Cini, R., 1986. Fenomeni di trasferimento e di flocculazione all'interfaccia acqua aria della superficie marina. Boll. Ocean. Teor. Appl. 4, $3-21$.

Loglio, G., Degli Innocenti, N., Tesei, U., Stortini, A.M., Cini, R., 1989a. Surfactant and particulated matter exchange at the air-water interface in Antarctic environment. Ann. Chim. 79, 571-587.

Loglio, G., Wang, Q.-S., DegliInnocenti, N., Tesei, U., Cini, R., 1989b. Rising of gas bubble in an aqueous medium in presence of surfactants. Il Nuovo Cimento 12C, 289-304.

Longwell, J., Maniece, W.D., 1955. Determination of anionic detergents in sewage effluents and river water. Analyst 80, 89-94.

MacCarthy, P., Suffet, I.H., 1989. Aquatic humic substances. Influence on fate and treatment of pollutants. In: Suffet, I.H., MacCarthy, P. (Eds.), Adv. Chem. Ser., 219, pp. XVII-XXX.

MacIntyre, F., 1970. Geochemical fractionation during mass transfer from sea to air by breaking bubbles. Tellus 22, 451-461.

MacIntyre, F., 1972. Flow patterns in breaking bubbles. J. Geophys. Res. 77, 5211-5288.

Mantoura, R.F.C., 1981. Organo-metallic interactions in natural waters. In: Duursma, E.K., Dawson, R. (Eds.), Marine Organic Chemistry. Elsevier, Amsterdam, pp. 179-223.

Pampaloni, B., Stortini, A.M., Sacco, C., Donato, R., Ademollo, B., Udisti, R., Cini, R., 1997. Biogeochemical evidence on Ca excess in marine aerosols. In: XIII International Symposium 
on Environmental Biogeochemistry 'Matter and Energy Fluxes in the Anthropocentric Environment'. Monopoli (Bari), Italy, September, 21-26.

Piotrowicz, S., Duce, R.A., Fasching, J., Weisel, C., 1979. Bursting bubbles and their effect on the sea-to-air transport of $\mathrm{Fe}$, $\mathrm{Cu}$ and $\mathrm{Zn}$. Mar. Chem. 7, 307-324.

Resch, F., 1986. Oceanic air bubbles as generator of marine aerosol. In: Monahan, E.G., Mac Niocaill, G. (Eds.), Oceanic Whitecaps and Their Role in Air-Sea Exchange Processes. Reidel, Dordercht, Holland, pp. 101-124.

Rivandeneyra, M.A., Delgado, D.R., Del Mural Ferrer, A.M., Ramos Comensana, A., 1994. Precipitation of calcium carbonate by vibrio spp from an inland saltern F.E.M.S. Microbial Ecology 13, 197-204.

Sakay, M., 1989. Ion distribution at nonequilibrium gas/liquid interface. J. Colloid Interface Sci. 127, 156-166.

Schiavuta, E., Mittner, P., Cini, R., 1992. Meteorological trigger and remote control in a meteomarine station for coastal sea pollution studies. In: Cardellicchio, N. Dell'Erba, F. (Eds.),
Proceedings of the Workshop 'Il monitoraggio automatico dell'inquinamento marino'. CNR-SCI, Taranto 9-10 April, pp. 313-330.

Senesi, N., 1990. Molecular and quantitative aspectes of the chemistry of fulvic acid and its interactions with metal oins and organic chemicals: Part II. The fluorescence spectroscopy approach. Analytica Chimica Acta 232, 77-106.

Skopincev, N.A., 1938. Organic matter in seawater and foam in the south-eastern part of Caspian Sea. Compt. Rend Doklady Akademii Nauk SSSR 18, 453-458.

Stuermer, D., Harvey, G., 1977. The isolation of humic substances and alcohol soluble organic matter from seawater. Deep Sea Res. 24, 303-309.

Szekielda, K., Kupferman, S., Klemas, V., Polis, D.F., 1972. Element enrichment in organic films and foams associated with aquatic frontal systems. J. Geophys. Res. 27, 5278-5282.

Weisel, C.P., Duce, R.A., Fashing, J.L., Heaton, R.W., 1984. Estimates of the transport of trace metals from the ocean to the atmosphere. J. Geophys. Res. 89, 11607-11618. 